\title{
FATORES DETERMINANTES PARA A SUCESSÃO FAMILIAR EM ESTABELECIMENTOS RURAIS DA REGIÃO OESTE DE SANTA CATARINA
}

\author{
Silvana Dalmutt Kruger ${ }^{1}$ \\ Maísa Aparecida Lemes da Silva² \\ Giana de Vargas Mores ${ }^{3}$ \\ Sérgio Murilo Petri ${ }^{4}$
}

\begin{abstract}
RESUMO
Esta pesquisa buscou identificar fatores determinantes para o processo de sucessão familiar em estabelecimentos rurais da região Oeste de Santa Catarina. O levantamento de dados contou com a aplicação de questionário a 200 respondentes dos estabelecimentos rurais dos municípios de Caxambu do Sul, Guatambu e Planalto Alegre. Em relação às características dos estabelecimentos, $80 \%$ possuem até 50 hectares e $23 \%$ já passaram pelo processo de sucessão familiar. Os resultados apontam os principais determinantes para o processo: rendimento financeiro das atividades rurais, oportunidade de crescimento e de rentabilidade dos negócios, recursos oferecidos pelo governo para subsidiar investimentos. A pesquisa evidenciou a importância dos rendimentos financeiros das atividades rurais, visando garantir renda satisfatória para a permanência dos jovens no meio rural e facilitar o processo de sucessão familiar.
\end{abstract}

Palavras-chave: agricultura familiar, contabilidade rural, população rural, sucessão familiar.

\section{DETERMINING FACTORS FOR THE PROCESS OF FAMILY SUCCESSION IN RURAL ESTABLISHMENTS IN THE WEST REGION OF SANTA CATARINA}

\begin{abstract}
This paper aimed to identify determining factors for the process of family succession in rural establishments in the West region of Santa Catarina. Data collection included the application of a questionnaire to 200 respondents from rural establishments in the municipalities of Caxambu do Sul, Guatambu and Planalto Alegre. Regarding the

\footnotetext{
${ }^{1}$ Graduada em Ciências Contábeis (UNOCHAPECÓ). Mestrado em Contabilidade (UFSC). Doutorado em Contabilidade (UFSC). Professora do Programa de Pós-Graduação em Ciências Contábeis e Administração (UNOCHAPECÓ). E-mail: silvanak@unochapeco.edu.br

${ }^{2}$ Graduada em Ciências Contábeis (UNOCHAPECÓ). E-mail: maisa_Isilva@unochapeco.edu.br

3 Graduada em Ciências Econômicas (UPF). Mestrado em Agronegócios (UFRGS). Doutorado em Agronegócios (UFRGS). Professora do Programa de Pós-Graduação em Administração (IMED Business School).E-mail: gimores@gmail.com

${ }^{4}$ Graduado em Ciências Contábeis (UNIVALI). Mestrado em Engenharia de Produção (UFSC). Doutorado em Engenharia de Produção (UFSC). Professor do Programa de Pós-Graduação em Contabilidade (UFSC). Email: smpetri@gmail.com
} 
characteristics of establishments, most of them (80\%) have up to 50 hectares, and it was observed that $23 \%$ have undergone the process of family succession. The results show the main determinants: financial income of rural activities, opportunity for growth and profitability of the business, and resources offered by the government to subsidize investments. This research highlights the importance of the financial income of the rural activities, in order to ensure a satisfactory income to the permanence of young people in rural areas and to facilitate the process of family succession.

Key-words: family farming, family succession, rural accounting, rural population.

\section{INTRODUÇÃO}

O agronegócio desempenha papel relevante no contexto da economia brasileira, uma vez que representa cerca de um quarto do produto interno bruto do país (CEPEA, 2018). A agricultura passa por diversas mudanças, sendo a profissionalização rural um exemplo disso. Muitos estabelecimentos rurais já possuem informações de apoio à gestão, contribuindo para análises de riscos referentes às atividades desenvolvidas e de resultados de cada cultivo (ALCÂNTARA; MACHADO FILHO, 2014).

Nos últimos anos, os produtores rurais passaram a se preocupar mais com a gestão agrícola e com a continuidade das atividades desenvolvidas nos estabelecimentos rurais. Dados do Censo Agropecuário 2017 (IBGE, 2018) indicam que a população rural brasileira corresponde a 15.036 .978 pessoas, sendo que $60,00 \%$ possuem idade entre 30 e 60 anos e $34,00 \%$ mais de 60 anos. Essa população está distribuída em 5.072.152 estabelecimentos rurais, em que $72,00 \%$ são caracterizados como produtores rurais (individuais). A idade da população rural indica que a longevidade dos estabelecimentos rurais dependerá das novas gerações, ressaltando a importância da sucessão familiar para a continuidade dos negócios rurais.

Os estudos de Silvestro et al. (2001), Stropasolas (2006), Flores Júnior e Grisci (2012), Alcântara e Machado Filho (2014), Breitenbach (2014), Krüger et al. (2014), Mera e Netto (2014), Panno e Machado (2014), Zanin et al. (2014) e Facioni e Pereira (2015) evidenciam que o processo sucessório é fundamental para a continuidade dos estabelecimentos rurais familiares, visto que são as novas gerações que determinarão o futuro desses estabelecimentos. Os estudos supracitados destacam, em sua maioria, a saída dos jovens da zona rural, dificultando a continuação das atividades e o processo sucessório. Nesse contexto, o objetivo desta pesquisa é o de identificar fatores determinantes para a sucessão familiar em estabelecimentos rurais da região Oeste de Santa Catarina.

Esta pesquisa considera a importância do processo de sucessão familiar para a gestão dos estabelecimentos rurais, bem como os desafios, tanto para a permanência dos jovens no meio rural, quanto para a continuidade das atividades desenvolvidas. Nos municípios do Oeste de Santa Catarina, Zanin et al. (2014) identificam que apenas 3,00\% dos jovens têm interesse em continuar as atividades rurais e apontam a carência do uso da contabilidade na gestão dos estabelecimentos rurais. Nesse sentido, destaca-se a relevância desta pesquisa sob o enfoque da identificação de fatores que possam contribuir com a sucessão familiar rural. 


\section{REVISÃO DA LITERATURA}

A sucessão familiar é o processo que acontece nas empresas familiares, em que as gerações mais novas assumem o comando das atividades, substituindo as mais experientes, ou seja, são os negócios que passam de uma geração para outra. Esse processo passa por diversos desafios, especialmente em relação à continuidade das empresas familiares (ALCÂNTARA; MACHADO FILHO, 2014).

$O$ processo de sucessão familiar é o momento em que os pais passam as suas funções para os seus sucessores, os filhos. De maneira geral, a sucessão familiar é considerada um fenômeno que ocorre na maioria das empresas familiares. Os sucessores precisam adquirir a competência e a experiência dos sucedidos. Além disso, a sucessão pode representar o momento em que o negócio receberá novas propostas, novas expectativas e uma visão mais inovadora (OLIVEIRA; ALBUQUERQUE; PEREIRA, 2012).

Poucas são as empresas familiares que sobrevivem às gerações seguintes: cerca de $30,00 \%$ chegam à segunda geração e menos de $15,00 \%$ à terceira geração (MARTINS et al., 2008). Essa situação ocorre, muitas vezes, por conflitos de interesse, divergências entre as visões estratégicas, fragilidades das informações entre os membros da família, o que acaba prejudicando as empresas no processo sucessório, fazendo com que muitas destas encerrem as suas atividades na primeira geração (MARTINS et al., 2008). O processo sucessório exige que os sucessores estejam capacitados para assumir os cargos de gestão e garantir a continuidade dos negócios familiares (MERA; NETTO, 2014; COSTA et al., 2015).

No contexto rural, a sucessão familiar também é um assunto latente, tendo em vista as características dos estabelecimentos rurais que empregam mão de obra familiar. A agricultura da região Oeste de Santa Catarina pode ser caracterizada pelo trabalho familiar, no entanto, essa característica vem tomando rumos diferentes. Os gestores rurais estão "envelhecendo", na maioria dos casos, pois os jovens, desmotivados em permanecer no campo, acabam migrando para a cidade em busca de melhores condições de vida (FACIONI; PEREIRA, 2015). Os motivos que levam os jovens a saírem do campo contemplam o tamanho dos estabelecimentos rurais, as terras insuficientes para o trabalho e as dificuldades de capital financeiro (MOREIRA; SCHLINDWEIN, 2016).

Segundo Mera e Netto (2014), a maior parte desse êxodo rural decorre da modernização e das mudanças tecnológicas, as quais estão presentes com maior frequência nos grandes estabelecimentos rurais. Os autores indicam que um dos motivos da diminuição dos jovens no meio rural refere-se ao incentivo dos pais para que seus filhos busquem um melhor nível educacional. No entanto, depois de formados, um número reduzido retorna para trabalhar na área rural.

De acordo com Facioni e Pereira (2015), o futuro das atividades agrícolas passa pela sucessão familiar. Entretanto, a falta de incentivo e as dificuldades de capital financeiro são fatores que prejudicam esse processo. Nesse contexto, destacase a importância de incentivar a permanência das novas gerações no campo, bem como orientar o processo de sucessão familiar, para que o mesmo ocorra de maneira espontânea e que as atividades dos estabelecimentos rurais possam ter continuidade.

Estudos realizados contribuem para a análise dos fatores que são determinantes para a sucessão familiar nos estabelecimentos rurais, a exemplo de Silvestro et al. (2001), Stropasolas (2006), Flores Júnior e Grisci (2012), Alcântara e Machado Filho (2014), Breitenbach (2014), Krüger et al. (2014), Laimer e Tonial (2014), Mera e Netto (2014), Panno e Machado (2014), Zanin et al. (2014), Facioni e Pereira (2015). Silvestro et al. (2001) e Stropasolas (2006) indicam que diversas mudanças no campo influenciam a saída dos jovens do meio rural, destacam os 
elevados custos de produção, o preço de venda dos produtos (abaixo da expectativa) e a escassez de oportunidades e de políticas públicas para incentivar a permanência dos jovens.

Alcântara e Machado Filho (2014) identificam o processo de sucessão em três empresas rurais. Dessa comparação, observou-se que a sucessão foi um processo de continuidade, tendo como facilitador a comunicação entre os sucessores. Um dos maiores desafios observados durante o estudo foi o interesse do jovem em permanecer na atividade agrícola e fazer parte do processo sucessório, pois muitos deles não acreditam que os investimentos nas atividades rurais possam the trazer benefícios e acabam deixando o campo. A pesquisa de Breitenbach (2014) discute os desafios enfrentados pela gestão rural, destacando a importância de se ter sucessores que estejam dispostos a assumir a gestão dos estabelecimentos rurais.

A pesquisa de Krüger et al. (2014) evidencia o uso da contabilidade como instrumento de gestão dos estabelecimentos rurais. A pesquisa foi realizada por meio de questionário aplicado à amostra de 150 produtores rurais do município de Erval Grande/RS. Os resultados mostram a fragilidade do uso da contabilidade como instrumento de gestão, tanto na identificação dos custos quanto na ausência da segregação das despesas particulares daquelas relativas à atividade econômica; assim como há falta de controles e relatórios para a análise dos resultados das atividades e o suporte ao processo decisório.

Mera e Netto (2014) analisam a diminuição da população rural do Alto Jacuí/RS. Para tanto, foram entrevistados 51 pequenos produtores rurais da região mencionada. Os resultados indicam que as melhores condições de vida na cidade atraem os olhares dos jovens, fazendo com que a maioria deixe o campo e passe a trabalhar nos centros urbanos. Essa situação ocorre porque os jovens não acreditam no sustento oriundo do estabelecimento rural e visualizam o meio urbano como um lugar melhor para se trabalhar. A pesquisa de Panno e Machado (2014) evidencia que a maioria dos jovens deixa o meio rural porque desacredita na continuação das atividades familiares. Para contornar essa situação, torna-se importante o incentivo gerado pelos pais, demonstrando as vantagens aos filhos para que permaneçam no estabelecimento rural e no desempenho das atividades.

Zanin et al. (2014) identificam as características da estrutura e da gestão dos estabelecimentos rurais do Oeste de Santa Catarina. A pesquisa foi aplicada em uma amostra de 210 proprietários rurais dos municípios de Quilombo, Coronel Freitas e Cordilheira Alta. Os resultados indicam que os estabelecimentos demonstram carência na utilização de controles contábeis, indicando fragilidades da estrutura organizacional e do processo de continuidade dos estabelecimentos. Destaca-se que, em $49,00 \%$ dos estabelecimentos, os filhos moram e trabalham com os pais e $59,00 \%$ dos respondentes pretendem permanecer no campo até o momento em que puderem trabalhar.

O estudo de Laimer e Tonial (2014) apresenta os fatores que influenciam na longevidade da empresa familiar, sendo que a pesquisa foi realizada na região Norte do Rio Grande do Sul. Os resultados mostram a influência direta de padrões comportamentais relacionados aos fatores familiares e de governança na longevidade da empresa familiar. A profissionalização é tida como uma alternativa para diminuir os conflitos sucessórios. Facioni e Pereira (2015) identificam fatores determinantes para a sucessão rural por meio de uma pesquisa no assentamento de Capão Bonito I, em Sindrolândia/MS, com a participação de 45 produtores rurais. Os resultados indicam que a falta de estrutura, os fatores financeiros, o baixo nível de escolaridade e a baixa valorização da agricultura fazem com que a maioria dos jovens deixe o campo em busca de melhores condições. 
De modo geral, os estudos evidenciam a importância da continuidade das atividades rurais, considerando a sua representatividade para a economia brasileira. Para tanto, é preciso inovar e investir na permanência dos jovens no meio rural, buscando alternativas que despertem neles a vontade de continuar as atividades rurais.

\section{PROCEDIMENTOS METODOLÓGICOS}

Esta pesquisa foi caracterizada como descritiva. Quanto aos procedimentos, foi empregada a pesquisa de levantamento. A população da pesquisa contemplou os habitantes rurais dos municípios de Guatambu/SC, Planalto Alegre/SC e Caxambu do Sul/SC.

Conforme os dados do Instituto Brasileiro de Geografia e Estatística (2010), o município de Guatambu possui 4.679 habitantes, sendo que 2.930 estão no meio rural; Planalto Alegre tem 2.654 habitantes e sua população rural é de 1.587 pessoas; Caxambu do Sul conta com 4.411 habitantes, sendo que 2.256 vivem na área rural. Esses dados totalizaram 6.773 habitantes no meio rural, atingindo-se uma amostra de 200 respondentes, definida pela acessibilidade e pela disposição dos habitantes em participar da pesquisa. A amostra foi composta por produtores rurais dos municípios de Guatambu (38,50\%), Caxambu do Sul (34,50\%) e Planalto Alegre $(27,00 \%)$.

$\mathrm{O}$ estudo caracterizou-se quanto à abordagem do problema como uma pesquisa quantitativa, visando a identificar os fatores determinantes para o processo de sucessão familiar rural. Com base nos objetivos propostos, foi elaborado um questionário com 21 questões fechadas como instrumento de coleta de dados, o mesmo foi impresso e entregue nas visitas feitas nos estabelecimentos rurais da região mencionada. Os questionários foram respondidos pelo produtor rural responsável, denominado como gestor rural (pais).

O período de aplicação do questionário compreendeu os meses de junho a agosto de 2016. A partir dos dados coletados foi possível definir os fatores determinantes da sucessão familiar nos estabelecimentos rurais em questão. Após a coleta de dados, os resultados foram organizados e apresentados por meio de tabelas, com a identificação das frequências absoluta e relativa das respostas. Cumpre destacar que as frequências relativas apresentadas nas Tabelas 4, 6, 10, 11 e 12 levaram em consideração o total de 200 respondentes, e não o total das respostas decorrente da multiplicidade de escolhas.

\section{ANÁLISE E INTERPRETAÇÃO DOS RESULTADOS}

Em um primeiro momento, a pesquisa apresenta as características dos respondentes e dos estabelecimentos rurais e, posteriormente, as características do processo de sucessão familiar. A Tabela 1 demonstra a faixa etária, o sexo, a escolaridade e o estado civil dos respondentes da pesquisa. 
Tabela 1 - Perfil dos proprietários rurais

\begin{tabular}{|c|c|c|}
\hline Idade & Frequência absoluta & Frequência relativa (\%) \\
\hline 16-19 anos & 87 & 43,50 \\
\hline $20-29$ anos & 73 & 36,50 \\
\hline 30-39 anos & 31 & 15,50 \\
\hline Acima de 40 anos & 9 & 4,50 \\
\hline Total & 200 & 100 \\
\hline Sexo & Frequência absoluta & Frequência relativa (\%) \\
\hline Masculino & 107 & 53,50 \\
\hline Feminino & 93 & 46,50 \\
\hline Total & 200 & 100 \\
\hline Escolaridade & Frequência absoluta & Frequência relativa (\%) \\
\hline $\begin{array}{l}\text { Ensino fundamental (até } 4^{\underline{a}} \\
\text { série) }\end{array}$ & 5 & 2,50 \\
\hline $\begin{array}{l}\text { Ensino fundamental ( } 5^{\mathrm{a}} \text { à } 8^{\mathrm{a}} \\
\text { série) }\end{array}$ & 23 & 11,50 \\
\hline $\begin{array}{l}\text { Ensino médio } \\
\text { Ensino superior }\end{array}$ & $\begin{array}{l}91 \\
81\end{array}$ & $\begin{array}{l}45,50 \\
40,50\end{array}$ \\
\hline Total & 200 & 100 \\
\hline Estado civil & Frequência absoluta & Frequência relativa (\%) \\
\hline Solteiro & 125 & 62,50 \\
\hline Casado & 70 & 35,00 \\
\hline Outro & 5 & 2,50 \\
\hline Total & 200 & 100 \\
\hline
\end{tabular}

Fonte: Dados da pesquisa.

De acordo com a Tabela 1, verifica-se que $43,50 \%$ dos respondentes são jovens com idade entre 16 a 19 anos, 36,50\% têm idade entre 20 e 29 anos. Quanto ao sexo, $53,50 \%$ são do sexo masculino e $46,50 \%$ do sexo feminino. Quanto à escolaridade, destaca-se que $45,50 \%$ possuem ensino médio, enquanto $40,50 \%$ possuem nível universitário ou estão cursando o ensino superior. Observando 0 estado civil, $62,50 \%$ são solteiros e $35,00 \%$ casados. A Tabela 2 indica o número de pessoas que forma o grupo familiar.

Tabela 2 - Número de pessoas do grupo familiar

\begin{tabular}{l|c|c}
\hline \multicolumn{1}{c|}{ Número de pessoas } & Frequência absoluta & Frequência relativa (\%) \\
\hline Duas & 15 & 7,50 \\
Três & 62 & 31,00 \\
Quatro & 84 & 42,00 \\
Acima de cinco & 39 & 19,50 \\
\hline Total & 200 & 100 \\
\hline
\end{tabular}

Fonte: Dados da pesquisa.

Foi possível observar o número de pessoas do grupo familiar, sendo que $42,00 \%$ das famílias são compostas por quatro pessoas e 31,00\% por três pessoas (Tabela 2). Na Tabela 3 observa-se o tamanho dos estabelecimentos rurais da amostra. 
Tabela 3 - Tamanho dos estabelecimentos rurais

\begin{tabular}{l|c|c}
\hline \multicolumn{1}{c|}{ Hectares } & Frequência absoluta & Frequência relativa (\%) \\
\hline $01-15$ & 57 & 28,50 \\
$16-25$ & 48 & 24,00 \\
$26-50$ & 55 & 27,50 \\
$51-75$ & 35 & 17,50 \\
Acima de 76 & 5 & 2,50 \\
\hline Total & 200 & 100 \\
\hline
\end{tabular}

Fonte: Dados da pesquisa.

A partir dos dados da Tabela 3, constatou-se que 28,50\% correspondem a estabelecimentos com até 15 hectares, 24,00\% possuem entre 16 a 25 hectares, $27,50 \%$ têm entre 26 e 50 hectares, e $20,00 \%$ têm área superior a 51 hectares. 0 tamanho dos estabelecimentos rurais é um fator importante na fase de sucessão familiar. Os respondentes que vivem em estabelecimentos menores afirmam que é difícil gerar renda superior, uma vez que a extensão de terra não é suficiente para grandes cultivos. A Tabela 4 apresenta as atividades desenvolvidas nos estabelecimentos analisados nesta pesquisa.

Tabela 4 - Atividades desenvolvidas nos estabelecimentos rurais

\begin{tabular}{l|c|c}
\multicolumn{1}{c|}{ Atividades } & $\begin{array}{c}\text { Frequência } \\
\text { absoluta }\end{array}$ & $\begin{array}{c}\text { Frequência relativa } \\
(\%)\end{array}$ \\
\hline Atividades agrícolas (plantação em geral) & 99 & 49,50 \\
Atividades zootécnicas (criação de animais) & 134 & 67,00 \\
Atividades agroindustriais (beneficiamento de & 20 & 10,00 \\
produtos) & 253 & -- \\
\hline Total & & \\
\hline
\end{tabular}

Fonte: Dados da pesquisa.

O questionamento da Tabela 4 possibilitava mais de uma opção de resposta. Assim, nota-se que $67,00 \%$ dos estabelecimentos desenvolvem atividades zootécnicas, destacando-se a produção leiteira. As atividades agrícolas são desenvolvidas em 49,50\% dos estabelecimentos da amostra e 10,00\% dos respondentes destacaram que desenvolvem atividades agroindustriais, que são entregues, na maioria das vezes, a cooperativas familiares ou mercados coloniais (como feiras para a comercialização de produtos da agricultura familiar ou mercado público). A Tabela 5 evidencia o faturamento médio anual das empresas rurais.

Tabela 5 - Faturamento médio dos estabelecimentos rurais

\begin{tabular}{l|c|c}
\multicolumn{1}{c|}{ Faturamento $(\mathrm{R} \$)$} & Frequência absoluta & Frequência relativa $(\%)$ \\
\hline Até $\mathrm{R} \$ 10.000,00$ & 7 & 3,50 \\
$\mathrm{R} \$ 10.001,00$ a $\mathrm{R} \$ 25.000,00$ & 17 & 8,50 \\
$\mathrm{R} \$ 25.001,00$ a $\mathrm{R} \$ 38.000,00$ & 30 & 15,00 \\
$\mathrm{R} \$ 38.001,00$ a $\mathrm{R} \$ 75.000,00$ & 63 & 31,50 \\
Acima de $\mathrm{R} \$ 75.001,00$ & 66 & 33,00 \\
Não souberam responder & 17 & 8,50 \\
\hline Total & 200 & 100 \\
\hline
\end{tabular}

Fonte: Dados da pesquisa.

De acordo com a Tabela 5, pode-se observar que $33,00 \%$ dos estabelecimentos rurais possuem faturamento superior a $R \$ 75.000,00$ anuais, enquanto $31,50 \%$ indicam faturamento anual de $R \$ 38.001,00$ a $R \$ 75.000,00$. Destaca-se que a renda familiar é um fator relevante para a permanência dos jovens. 
A pesquisa realizada por Alcântara e Machado Filho (2014) corrobora com os achados deste artigo, evidenciando que muitos jovens não acreditam que os investimentos nas atividades rurais possam lhe trazer benefícios, por isso acabam deixando o campo. Os resultados indicam que $12,00 \%$ dos estabelecimentos rurais possuem renda de até $\mathrm{R} \$ 25.000,00$ ao ano, que pode ser insuficiente para algumas famílias. A Tabela 6 evidencia os controles financeiros realizados nos estabelecimentos rurais, lembrando que a questão possibilitava mais de uma opção de resposta.

Tabela 6 - Controles financeiros dos estabelecimentos rurais

\begin{tabular}{|c|c|c|}
\hline Controles dos estabelecimentos & $\begin{array}{c}\text { Frequência } \\
\text { absoluta }\end{array}$ & $\begin{array}{c}\text { Frequência relativa } \\
(\%)\end{array}$ \\
\hline $\begin{array}{l}\text { Controle de gastos com máquinas e } \\
\text { equipamentos }\end{array}$ & 32 & 16,00 \\
\hline Controle de gastos com compra de insumos & 49 & 24,50 \\
\hline $\begin{array}{l}\text { Controle de caixa, relacionando todos os } \\
\text { pagamentos }\end{array}$ & 87 & 43,50 \\
\hline $\begin{array}{l}\text { Separação dos gastos do estabelecimento } \\
\text { com os da família }\end{array}$ & 26 & 13,00 \\
\hline Não realiza controle & 35 & 17,50 \\
\hline Total & 229 & -- \\
\hline Fazem uso dos controles & $\begin{array}{l}\text { Frequência } \\
\text { absoluta }\end{array}$ & $\begin{array}{c}\text { Frequência relativa } \\
(\%)\end{array}$ \\
\hline Sim, fazemos uso de controles internos & 91 & 45,50 \\
\hline $\begin{array}{l}\text { Sim, gostaríamos de implantar novos } \\
\text { controles }\end{array}$ & 85 & 42,50 \\
\hline Não, os controles são difíceis de serem feitos & 24 & 12,00 \\
\hline Total & 200 & 100,00 \\
\hline
\end{tabular}

Fonte: Dados da pesquisa.

Observando a Tabela 6 , verifica-se que $43,50 \%$ dos respondentes realizam o controle de caixa, relacionando os pagamentos que ocorreram durante o desenvolvimento das atividades. Dos respondentes, 13,00\% dizem fazer a separação dos gastos dos estabelecimentos dos gastos familiares e $17,50 \%$ não realizam nenhum tipo de controle. Na sequência, $42,50 \%$ dos respondentes indicaram que gostariam de implantar controles para a gestão rural. Nota-se que carecem de treinamentos e capacitações em relação à gestão, pois muitas não separam os gastos das atividades rurais dos gastos familiares, o que dificulta a identificação dos resultados.

Os achados desta pesquisa corroboram com os de Zanin et al. (2014), que observou a carência da utilização de controles contábeis, sendo que poucos estabelecimentos realizam algum tipo de controle, ou muitas não sabem identificar quais são os controles a serem realizados. As finalidades da contabilidade indicadas pelos respondentes são apresentadas na Tabela 7.

Tabela 7 - Finalidades da contabilidade

\begin{tabular}{l|c|c}
\multicolumn{1}{c|}{ Finalidades } & Frequência absoluta & Frequência relativa (\%) \\
\hline Prestar contas ao fisco & 80 & 40,00 \\
Auxiliar no processo de gestão das & 97 & 48,50 \\
atividades & 23 & 11,50 \\
Desconhece as finalidades & 200 & 100,00 \\
\hline Total &
\end{tabular}

Fonte: Dados da pesquisa. 
Com base na Tabela 7 , observa-se que $11,50 \%$ dos gestores rurais não conhecem a principal finalidade da contabilidade para o meio rural, como destacam $51,50 \%$ dos respondentes; embora $48,50 \%$ dos respondentes acreditam que a principal finalidade da contabilidade é auxiliar no processo de gestão das atividades. Esses resultados assemelham-se aos resultados da pesquisa de Krüger et al. (2014), a qual destaca a fragilidade do uso da contabilidade como instrumento de gestão dos estabelecimentos rurais. As informações da Tabela 8 destacam os objetivos profissionais dos respondentes.

Tabela 8 - Pretensão para o futuro

\begin{tabular}{l|c|c}
\hline \multicolumn{1}{c|}{ O que deseja para o futuro } & $\begin{array}{c}\text { Frequência } \\
\text { absoluta }\end{array}$ & $\begin{array}{c}\text { Frequência } \\
\text { relativa (\%) }\end{array}$ \\
\hline Permanecer na agricultura como proprietário rural & 82 & 41,00 \\
e dar continuidade às atividades da família & & 13,50 \\
Morar no meio rural e desenvolver atividades & 27 & 23,50 \\
agropecuárias & 47 & 22,00 \\
Morar no campo, mas trabalhar na cidade & 44 & 100,00 \\
Sair do campo, morar e trabalhar na cidade & 200 &
\end{tabular}

Fonte: Dados da pesquisa.

Do total de entrevistados, $41,00 \%$ desejam permanecer na agricultura como proprietários rurais e dar continuidade às atividades da família no meio rural. Identificou-se também que: $23,50 \%$ preferem morar no campo, mas trabalhar no meio urbano; $22,00 \%$ dos respondentes pensam em sair do campo, morar e trabalhar na cidade.

Dos proprietários ou filhos de proprietários, 68,00\% sinalizam ter recebido estímulo para ficar no campo, dando continuidade às atividades rurais, enquanto $32,00 \%$ afirmam não ter recebido esse incentivo. Os resultados obtidos assemelhamse às pesquisas de Mera e Netto (2014) e Panno e Machado (2014), as quais destacam que a maioria dos jovens deixa o meio rural por desacreditar na continuação das atividades familiares, indicando o meio urbano como a melhor opção. Os autores evidenciam também a importância do incentivo dos pais para a permanência dos jovens no meio rural, visando a promover o processo de sucessão familiar.

Nesse aspecto, os respondentes foram questionados se acreditam que as famílias podem tirar o seu sustento das atividades rurais, a saber: $79,50 \%$ indicaram que sim, que as famílias podem tirar o sustento do meio rural a partir das atividades desenvolvidas; $20,50 \%$ afirmaram que não, alegando que os rendimentos são inferiores, se comparados com os custos e as despesas que se têm para produzir e manter o estabelecimento rural. Na Tabela 9, evidenciam-se as características e os fatores do processo de sucessão familiar. 
Tabela 9 - Sucessão familiar e os fatores para esse processo

\begin{tabular}{l|c|c}
\hline \multicolumn{1}{c|}{ A família já falou sobre sucessão familiar } & $\begin{array}{c}\text { Frequência } \\
\text { absoluta }\end{array}$ & $\begin{array}{c}\text { Frequência } \\
\text { relativa (\%) }\end{array}$ \\
\hline Sim & 65 & 32,50 \\
Não & 89 & 44,50 \\
O estabelecimento já passou por sucessão familiar & 46 & 23,00 \\
\hline Total & 200 & 100,00 \\
\hline$\quad$ Fatores para o processo de sucessão familiar & & \\
\hline Localização do estabelecimento próximo à cidade & 44 & 22,00 \\
Rendimento financeiro das atividades rurais & 133 & 66,50 \\
Estrutura dos estabelecimentos rurais & 57 & 28,50 \\
Incentivo dos pais e familiares para continuar as & 47 & 23,50 \\
atividades rurais & 59 & 29,50 \\
Recursos oferecidos pelo governo para subsidiar & & 31,50 \\
investimentos & 63 & \\
Oportunidade de crescimento e rentabilidade dos & & -- \\
negócios & 403 & \\
\hline Total & & \\
\hline
\end{tabular}

Fonte: Dados da pesquisa.

$\mathrm{Na}$ Tabela 9, identifica-se que $44,50 \%$ dos gestores rurais ainda não mencionaram sobre o processo de sucessão familiar, ou seja, não houve diálogo entre pais e filhos sobre esse processo. Dos estabelecimentos rurais da amostra, $23,00 \%$ indicam que o estabelecimento já passou por algum processo de sucessão, enquanto $32,50 \%$ falam sobre sucessão, mas ainda não passaram pelo processo. Os resultados observados corroboram com a pesquisa de Flores Júnior e Grisci (2012), ao destacar que um dos fatores que dificulta a sucessão familiar rural é o pouco diálogo sobre o assunto entre pais e filhos.

Os principais fatores para o processo de sucessão familiar nos estabelecimentos rurais são evidenciados pelos respondentes: rendimento financeiro das atividades rurais, oportunidade de crescimento e de rentabilidade dos negócios, recursos oferecidos pelo governo para subsidiar investimentos e estrutura dos estabelecimentos rurais. A Tabela 10 traz os fatores destacados para a permanência dos jovens no meio rural.

Tabela 10 - Permanência dos jovens no meio rural

\begin{tabular}{l|c|c}
\hline Fatores da permanência dos jovens no & Frequência absoluta & Frequência relativa (\%) \\
\hline Dificuldade de arrumar outro emprego & 46 & 23,00 \\
Ser dono do próprio negócio & 109 & 54,50 \\
Custo de vida mais barato & 69 & 34,50 \\
Ficar próximo à família & 83 & 41,50 \\
Qualidade de vida no meio rural & 71 & 35,50 \\
Gostar do que faz no meio rural & 128 & 64,00 \\
Rentabilidade das atividades & 80 & 40,00 \\
desenvolvidas & & \\
\hline Total & 586 & --
\end{tabular}

Fonte: Dados da pesquisa.

Os respondentes acreditam que o principal fator para a permanência dos jovens no campo está no fato de gostar do que faz, assim como ser dono do próprio negócio e ficar próximo à família (Tabela 10). Um percentual importante de respondentes indicou que a sua permanência no meio rural está atrelada à 
rentabilidade das atividades desenvolvidas. Quanto às dificuldades percebidas para o processo de sucessão familiar nos estabelecimentos participantes, apresenta-se a Tabela 11.

Tabela 11 - Dificuldades no processo de sucessão familiar rural

\begin{tabular}{l|c|c}
\hline \multicolumn{1}{c|}{$\begin{array}{c}\text { Fatores que dificultam o processo de } \\
\text { sucessão familiar }\end{array}$} & $\begin{array}{c}\text { Frequência } \\
\text { absoluta }\end{array}$ & $\begin{array}{c}\text { Frequência relativa } \\
(\%)\end{array}$ \\
\hline $\begin{array}{l}\text { Localização do estabelecimento rural } \\
\text { Tamanho do estabelecimento rural }\end{array}$ & 30 & 15,00 \\
Falta de incentivo dos pais para continuar no & 106 & 53,00 \\
meio rural & 48 & 24,00 \\
Falta de recursos para financiar os & 41 & 20,50 \\
investimentos & 46 & 23,00 \\
Falta ou carência de tecnologias & 83 & 41,50 \\
Baixo rendimento financeiro das atividades & & 37,50 \\
rurais & 75 & 10,00 \\
Falta de valorização do produtor rural & 20 & 20,50 \\
Escassez de lazer no meio rural & 41 & 22,00 \\
Dificuldades do trabalho agrícola & 44 & 15,00 \\
Incertezas quanto à renda e ao resultado das & 30 & 0,50 \\
atividades & 1 & -- \\
Não gosta do meio rural & 565 & \\
Outros & & \\
\hline Total & &
\end{tabular}

Fonte: Dados da pesquisa.

A Tabela 11 compreende os fatores que podem dificultar o processo de sucessão familiar nos estabelecimentos rurais analisadas, entre os principais estão: 0 tamanho do estabelecimento, o baixo rendimento financeiro das atividades rurais, a falta de valorização do produtor rural, a falta de incentivo dos pais para os filhos continuarem no meio rural, a carência de tecnologias no estabelecimento rural. As mudanças climáticas e os fenômenos naturais podem comprometer a produção de um estabelecimento, assim os respondentes destacam que as incertezas quanto à renda e ao resultado das atividades podem dificultar a continuação das atividades rurais.

Os resultados desta pesquisa vão ao encontro aos de Facioni e Pereira (2015), uma vez que a falta de estrutura do estabelecimento rural, os fatores financeiros e a falta de valorização dos agricultores fazem com que a maioria dos jovens deixe o campo. A Tabela 12 traz as respostas sobre as possibilidades de transferência de posse do estabelecimento rural, caso ocorra a sucessão familiar.

Tabela 12 - Transferência do estabelecimento rural

\begin{tabular}{l|c|c}
\hline \multicolumn{1}{c|}{ Transferência do estabelecimento rural } & $\begin{array}{c}\text { Frequência } \\
\text { absoluta }\end{array}$ & $\begin{array}{c}\text { Frequência } \\
\text { relativa (\%) }\end{array}$ \\
\hline $\begin{array}{l}\text { Quando os pais tiverem uma renda garantida } \\
\text { (aposentadoria) }\end{array}$ & 40 & 20,00 \\
$\begin{array}{l}\text { Quando o sucessor estiver pronto para assumir as } \\
\text { responsabilidades }\end{array}$ & 33 & 16,50 \\
Não será feita transferência enquanto os pais \\
tiverem condições de gerir o estabelecimento
\end{tabular}

Fonte: Dados da pesquisa. 
A Tabela 12 indica que para $20,00 \%$ dos respondentes o estabelecimento rural será transferido somente para um sucessor no momento em que os pais estiverem aposentados e com uma renda garantida; $16,50 \%$ indicam que a transferência ocorrerá quando o sucessor estiver pronto para assumir os negócios; $15,50 \%$ não transferirão a posse do estabelecimento enquanto os pais tiverem condições de administrá-la; $48,00 \%$ dos respondentes ainda não mencionaram sobre o processo de sucessão familiar entre os membros da família. O último resultado indica que pais e filhos não estão discutindo a sucessão, adiando a decisão e o seu planejamento, com consequências para o empreendimento rural, como o adiamento de investimentos e, muitas vezes, com a migração do potencial sucessor, causada pela indefinição de funções e perspectivas.

Os resultados obtidos convergem com os achados de Breitenbach (2014), em que se destaca a importância da transferência do estabelecimento rural para um sucessor, desde que o mesmo esteja disposto a assumir a gestão. Também corroboram com os resultados da pesquisa de Laimer e Tonial (2014), a qual destaca que o processo de sucessão familiar e a longevidade dos negócios são influenciados por fatores familiares e de governança.

\section{CONSIDERAÇÕES FINAIS}

Em relação ao processo de sucessão familiar nos estabelecimentos rurais analisados, foram identificados os principais determinantes para o processo de sucessão familiar nos estabelecimentos rurais dos três municípios da região Oeste de Santa Catarina: rendimento financeiro das atividades rurais, oportunidade de crescimento e de rentabilidade dos negócios, recursos oferecidos pelo governo para subsidiar investimentos, estrutura dos estabelecimentos rurais. Os respondentes acreditam que um dos principais fatores para a permanência dos jovens no campo está no fato de gostar do que faz no meio rural, assim como ser dono do próprio negócio e ficar próximo à família.

Em contrapartida, destacam-se os fatores restritivos para o processo de sucessão familiar: tamanho do estabelecimento rural, baixo rendimento financeiro das atividades rurais, baixa valorização do produtor rural. Nesse cenário, evidencia-se a necessidade de pesquisas que possam demonstrar alternativas para o planejamento do processo de sucessão familiar e da gestão dos estabelecimentos rurais, visando a incentivar a permanência do jovem no meio rural e a continuidade dos negócios desenvolvidos no campo.

As dificuldades no processo de sucessão familiar podem comprometer a produção de alimentos, uma vez que os estabelecimentos rurais fornecem boa parte da matéria-prima utilizada nas agroindústrias, assim como a agricultura desempenha um papel socioeconômico relevante ao contribuir com geração de empregos e renda. Diante disso, também se destaca a importância de políticas públicas de apoio à gestão rural, para que as gerações mais novas estejam motivadas a permanecer no campo e garantir a continuidade dos estabelecimentos rurais por meio da sucessão familiar.

\section{REFERÊNCIAS}

ALCÂNTARA, N. B.; MACHADO FILHO, C. A. P. O processo de sucessão no controle de empresas rurais brasileiras: um estudo multicasos. Organizações Rurais \& Agroindustriais, v. 16, n. 1, p. 139-151, 2014.

BREITENBACH, R. Gestão rural no contexto do agronegócio: desafios e limitações. Desafio Online, v. 2, n. 2, p. 714-731, 2014. 
CENTRO DE ESTUDOS AVANÇADOS EM ECONOMIA APLICADA. Escola Superior de Agricultura Luiz de Queiroz, Universidade de São Paulo. PIB do agronegócio brasileiro de 1996 a 2018. Piracicaba, 2018. Disponível em http://www.cepea.esalq.usp.br/br/pib-do-agronegocio-brasileiro.aspx. Acesso em: 11 fev. 2019.

COSTA, L. S. P. De pai para filho: a sucessão em pequenas e médias empresas familiares. Contabilidade, Gestão e Governança, v. 18, n. 1, p. 61-82, 2015.

FACIONI, D.; PEREIRA, M. W. G. Análise dos determinantes da sucessão em assentamento rural no Estado de Mato Grosso do Sul. Organizações Rurais \& Agroindustriais, v. 17, n. 1, p. 119-136, 2015.

FLORES JÚNIOR, J. E.; GRISCI, C. L. I. Dilemas de pais e filhos no processo sucessório de empresas familiares. Revista de Administração (São Paulo), v. 47, n. 2, p. 325-337, 2012.

INSTITUTO BRASILEIRO DE GEOGRAFIA E ESTATÍSTICA - IBGE. Censo agropecuário 2017. Disponível em: https://censos.ibge.gov.br/agro/2017/templates/censo_agro/resultadosagro/index.ht ml. Acesso em: 11 fev. 2019.

KRÜGER, S. D. et al. A contabilidade como instrumento de gestão dos estabelecimentos rurais. Reunir: Revista de Administração, Contabilidade e Sustentabilidade, v. 4, n. 2, p. 134-153, 2014.

LAIMER, C. G.; TONIAL, R. B. Os padrões comportamentais que influenciam na longevidade da empresa familiar. Revista de Administração IMED, v. 4, n. 1, p. 123140, 2014.

MARTINS, A. et al. Empresa familiar e as dificuldades enfrentadas pelos membros da terceira geração. Revista de Ciências da Administração, v. 10, n. 22, p. 30-54, 2008.

MERA, C. M. P.; NETTO, C. G. M. A diminuição da população rural na região do Alto Jacuí/RS: análise sob a perspectiva dos segmentos rurais. Desenvolvimento em Questão, v. 12, n. 27, p. 216-263, 2014.

MOREIRA, F. G.; SCHLINDWEIN, M. M. Sucessão da gestão na agricultura familiar: um estudo de caso no assentamento de Santa Olga no município de Nova Andradina em Mato Grosso do Sul. Revista Nera, v. 18, n. 29, p. 151-173, 2016.

OLIVEIRA, J. L.; ALBUQUERQUE, A. L.; PEREIRA, R. D. Governança, sucessão e profissionalização em uma empresa familiar: (re)arranjando o lugar da família multigeracional. Revista Brasileira de Gestão de Negócios, v. 14, n. 43, p. 176-192, 2012.

PANNO, F.; MACHADO, J. A. D. Influências na decisão do jovem trabalhador rural partir ou ficar no campo. Desenvolvimento em Questão, v. 12, n. 27, p. 264-297, 2014. 
SILVESTRO, M. L. et al. Os impasses sociais da sucessão hereditária na agricultura familiar. Florianópolis: Epagri; Brasília: Nead/Ministério do Desenvolvimento Agrário, 2001.

STROPASOLAS, V. L. O mundo rural no horizonte dos jovens. Florianópolis: UFSC, 2006.

ZANIN, A. et al. Gestão das propriedades rurais do Oeste de Santa Catarina: as fragilidades da estrutura organizacional e a necessidade do uso de controles contábeis. Revista Catarinense da Ciência Contábil, v. 13, n. 40, p. 09-19, 2014. 